\title{
Post-intensive Care Syndrome in COVID 19: Monitoring from the Physical Medicine and Rehabilitation and Clinical Psychology
}

\section{Espinosa-Gil Rosa María ${ }^{\mathbf{1 *}}$ and Monteagudo-Santamaría María ${ }^{2}$}

${ }^{1}$ Clinical Psychologist, Physical Medicine and Rehabilitation Service, Virgen de la Arrixaca University Hospital, Murcia Spain

${ }^{2}$ Head of Service, Physical Medicine and Rehabilitation, Virgen de la Arrixaca University Hospital, Murcia, Spain

*Corresponding Author: Espinosa-Gil Rosa María, Clinical Psychologist, Physical Medicine and Rehabilitation Service, Virgen de la Arrixaca University Hospital, Murcia Spain.
Received: July 10, 2020

Published: August 12, 2020

(C) All rights are reserved by Espinosa-Gil

Rosa María and Monteagudo-Santamaría

María.

\begin{abstract}
The Covid-19 has been a great challenge. At this time, it is interesting to approach patients with severe COVID who have required prolonged admission to the Critical Care Unit (ICU), intubation with connections to mechanical respiration, even connection to the extracorporeal oxygenation membrane (ECMO), because our hospital (Virgen de la Arrixaca, University Hospital, in Murcia), is reference for connection to ECMO.

We have elaborated a process/protocol for offering physical and psychological care (assessment, diagnosis and treatment) from the hospital environment and specifically from Rehabilitation Service. This constitutes a challenge and we consider that it will have a significant improvement in both physical and psychological symptoms.

We are working in the context to Post ICU Syndrome.

The sample is reduced by the severity of the patients.

We cannot offer results due to the recent pandemic and because in our region it occurred one month later than in the rest of the most affected regions in Spain (Madrid, Barcelona, Bilbao). We are in the first medical and psychological evaluations and treatment in the actuality.
\end{abstract}

Keywords: Rehabilitation; Sars Covid-19; PTSD; Family Therapy; ICU Acquired Weakness

\section{Abbreviations}

Post ICU: Intensive Critical Unit Syndrome After; PTSD: Posttraumatic Stress Disorder; SCCM: Society Critical Care American; PICS: Post ICU Syndrome; PICS-F: Post ICU Syndrome Family; NICE: National Institute for Health and care Excellence guide; ICD: International Classification of Diseases (WHO); DSM: Diagnostic and Statistical Manual of Mental Disorders American Psychiatric Association (APA); AVD: Daily Life Activities; DRMO: Desensitization and Reprocessing of Eye Movement

\section{Introduction}

The impressive wave of infections that has occurred in our country by Covid 19, has triggered not only physical problems (which have already been documented since the start of the pan- demic), but on a psychological level, the WHO even affirming that we are in a pandemic of mental disorders.

Offering physical and psychological care (assessment, diagnosis and treatment) from the hospital environment and specifically from Rehabilitation Service constitutes a challenge and we consider that it will have a significant improvement in both physical and psychological symptoms.

Before the Covid 19 Pandemic, the American Critical Care Society (SCCM) defined Post ICU Syndrome (PICS) an "New or worsening physical, mental or cognitive health problems related to critical illness that persist at discharge from the hospital in the survivor". In addition, PICS was linked to the family member or caregivers 
(PICS-F) as a result of critical illness they can develop complications in their mental health [1]. It is within this framework that we want to offer our services to patients and families. A group of authors recommend the intervention of rehabilitation clinicians (doctors and mental health specialists) together and deal with post ICU syndrome. Regarding care for families, once the patient has survived the disease, it is necessary to review their emotional states and not pathologize the normal emotional reactions of the family members, and it is necessary to establish clear and agreed criteria with all the professionals involved to determine whether intervening is more beneficial than not doing it [1-3].

\section{Physical and psychological impact of ICU stay}

The respiratory involvement associated with COVID-19 presents symptoms of viral pneumonia that can evolve to exudative consolidations, mucous hypersecretion and difficulty in eliminating secretions. In more advanced stages, with the presence of ARDS, surviving patients may have long-term clinical, functional, and morphological pulmonary squeals, with a decrease in healthrelated quality of life [4]. The first follow-up series in patients with COVID 19 show functional alterations in lung functional capacity ad radiological alterations compatible with pulmonary fibrosis [5]. Alteration in the activities of daily life, in instrumental activities. This disability, such as making the purchase, occurred in $70 \%$ of ICU survivor who required ventilation for more than 48 hours and these disabilities are correlated with the age of patient [6]. These authors establish that the risk factors that are related to the ICU stay are treatment with corticosteroids, nosocomial diseases, and slow resolution of lung conditions. They also do not forget that neuromyopathic disease, muscular atrophy. Aspects related to immobilization have their affects at the muscular level. Recommending early rehabilitation $[6,7]$.

Psychological impact (Current situation against COVID 19)

The hospitalization of a loved one, and more specifically in a critical care unit, generates changes in perception, thoughts and feelings, even disruptive consciousness such as POST-ICU Syndrome (PICS), which it affects the critical ill hospitalized patients and was created by Society of Critical Medicine [8].

When a serious illness confronts us with processes of defenselessness, where the only thing we can do is trust health specialists and the locus of control becomes external, modification arise in the internal beliefs of "I can control my life" to "a situation of total uncontrollability". Believing in a just world makes us feel that maintain control over things and it is precisely this that is altered and modified. If you (for example) have a lung cancer, it is because you are a smoker (in some way this calms us down), but in the case at hand our mental schemas are modified. This entails a significant cost in terms of stress, anxiety and depressive symptoms.

In the case of an invisible disease, alarms go off and generate depressive processes, where sometimes specialized human resources are needed to accompany both the patient who has suffered from an infectious disease that is still unknown their way of proceeding, and high mortality, and the transmission of information (through mass media) generate anxiety and probably phobic-anxious processes. Specific phobias can be acquired in three ways: classical conditioning, instrumental and by transmission of information [9]. The transmission of threatening information (such as the subject at hand) also generates a possibility of developing phobias, being less powerful (compared to the rest of mechanisms) but that could interact with the rest (classical conditioning, instrumental).

There are studies on family members who have to make decisions in intensive care and have a higher level of anxiety, and higher prevalence of Post ICU syndrome [10].

The National Institute for Health and Care Excellence guide NICE (2018) [11] advise active monitoring for the first month after exposure to potential trauma before intervening. If the person showed psychopathological signs after that time, it would be advisable to consult with specialized professionals.

It is important to assess and identify all risk groups and offer intervention to their specific needs [3].

To conclude and following the recommendations of the Spanish Society of rehabilitation and Physical Medicine [12], rehabilitation should be seen as a continuum of care with an early preventive approach over time and a fallow-up in the ICU and the hospital, which follow-up outpatient, including post-ICU multidisciplinary consultation.

\section{Objective of the Study \\ Main objective}

To be able to detect physical, emotional, psychopathology and cognitive deterioration risk factors to be able to intervene early after discharge from the critical care unit for having Covid 19, from the Physical Medicine and Rehabilitation service, to improve the patient's quality of the life and their families.

\section{Specific objectives}

- Assess functional capacity and level of independence in activities of daily living. 
- Intervene at different levels according to physical symptoms from rehabilitation (at skeletal, neurological, respiratory muscle level) and address the problems of impaired swallowing.

- Carry out cognitive evaluation of screening through different tests that allow estimating deficits in executive functions and memory.

- Offer cognitive intervention to improve undetected deficits.

- Analyze if the patient and/or family DSM 5 criteria for PTSD. GAD and/or depressive disorder.

- $\quad$ Perform individual psychotherapy (if applicable after analysis of the results of the applied test and risk factors).

- Offer systemic family therapy within the service if necessary.

\section{Materials and Methods}

Study design

A prospective longitudinal study of patients and families with COVID 19 will be performed. It is a quasi-experimental design with a study before treatment and after. We cannot randomly assign subjects to treatments due to low sample size.

\section{Study sample}

These are serious subjects who have required prolonged admission to the Critical Care Unit with mechanical respiration and who have been cared by Rehabilitation Service since the disconnection of the ICU ventilator (earing) begins.

Patients who have been admitted to the ICU of the Virgen de la Arrixaca Hospital in Murcia, will be followed up during the period from 2020 to 2022 for 24 months from the date of inclusion. According to clinical and diagnostic criteria, the pertinent treatment and/or referral to other specialists in mental health or medicine will be carried out.

\section{Treatment}

Subjects will be assigned to both physical and psychological treatments according to ICD 10 and DSM 5 diagnostic criteria.

\section{Inclusion criteria}

- Patients diagnosed with COVID 19 infection

- Prolonged ICU admission with need of mechanical ventilation

- Having been treated by rehabilitation service from the moment the respirator was disconnected.

\section{Exclusion criteria}

The patients with psychopathological disorders that they are receiving psychotherapy previously.

Cognitive impairment moderate or severe prior to admission.

The sample and associated data will be kept under the appropriate security conditions and it is guaranteed that the subjects cannot be identified through means considered reasonable bay person other than those authorized.

Method/proceeding

Subjects will be recruited

- First contact: Written document at home explaining the fundamental aspects of the examination of the post-ICU syndrome and informing that they will shortly receive a phone call from the Rehabilitation Doctor and from the Clinical Psychologist state and to be able to offer according to the results of the explorations, a personalized and at the same time familiar attention.

- Telephone interview (one week after writing): Data collection will be carried out though a personal interview and with the family member of the patient who was admitted to the ICU after medical discharge (telephone interview) and one month in person.

During this period, ad-hoc questionnaires will be prepared and completed that will include:

- Sociodemographic and clinical variables: Data affiliation, age, sex, educational level, work activities, level of health and social situation. Number of days in ICI, number of days in the plan and number of days that elapsed since discharge.

- Clinical variables: Anxiety level, history of previous psychopathological disease, diseases such as diabetes mellitus, obesity, hypertension, sleep disorders, personality disorders or some axis I disorders according DSM IV TR.

E-mail

In the event that patients live outside the Murcia, they will be provided (as far as possible) and via email, the questionnaires that are necessary to explore all the factors that may be influencing a decrease in their quality of life and we will call again after sending them on time. 
Face to face interview (medical, and Psychological Evaluation on month after discharge.

Before all intervention the patient and family have to sing informed consent.

According to the variables analyzed, although medical appointments will be used to save patients numerous visits, when start psychological treatment visits will be made biweekly to assess the significant clinical improvement.

From a medical point of view, visits will be structured at one month, three months and on year of follow-up.

Medical/physiotherapy and psychological treatment as preceded by monthly appointment

\section{Assessment instruments}

Medicine

- Gait speed test

- $\quad$ Timed test get up and walk

- Barthel index

- $\quad$ Fried fragility scale

- Dynamometry (evaluation of peripheral musculature)

- Dumbbelset

- Medicine ball

- $\quad$ Echograh (diaphragmatic assessment)

- Cycle ergometer

- Valve device for potentiation of inspiratory muscles (threshold)

- $\quad$ Treadmill.

Psychological instruments

- Folstein Mini Mental MMSE Cognitive exam it is one of the most widely used methods to detect cognitive impairment and monitor its evolution in patient with neurological disorder [13].

- Frontal assessment Battery [14]. There are multiple pathologies, neurological that can affect the function of the frontal lobe stroke, traumatic brain injuries, neoplasms, viriasis, surgical ablation, neurodegenerative diseases and certain subtypes of psychopathology.

- Weschler Memory Scale III (Subtest Word List I and II) [15].
- $\quad$ Trail making test Form A y Form B [16]. The trace test is a neuropsychological test that aims to evaluate different cognitive functions, including attention, psychomotor and cognitive flexibility.

- Hospital anxiety and depression scale [17].

- $\quad$ Beck depression inventory (BDI) [18].

- $\quad$ Revised symptom severity scale (EGS_R) for post traumatic stress disorder according to DSM 5 [19].

- $\quad$ EQ-5 D [20].

- $\quad$ ESFA family satisfaction scale for adjectives [21].

- Evaluation and assessment of interpersonal links in Adults VICULATEST [22].

\section{Results and Discussion}

Statistical data analysis

Although the sample size is small, we believe that it will shed light on new research on the POST-ICU intervention in COVID 19, both physical and psychological.

Treatment medical and psychological

Psychological

In Post- traumatic Stress disorder: Trauma-based cognitive behavioral therapy (8 sessions according to scientifics recommendations [23].

Desensitization and reprocessing of eye movement (DRMO), based on the groups integrative protocol for continued post- traumatic stress [24].

In generalized anxiety disorder

Assessment of the severity of the disorder and referral in cases where psychotherapy needs a more specific intervention to Mental Health Center.

\section{In depressive disorder}

Cognitive behavioral therapy, Behavioral activation therapy. Mindfulness techniques to reduce stress.

\section{A family Level}

Systemic family therapy (when deemed appropriate).

At the physical level

- Physical treatment of sarcopenia and musculoskeletal disorders (mobilization, muscle enhancement, proprioception, reeducation for balance and gait, electro stimulation). 
- $\quad$ Respiratory kinesitherapy to improve respiratory volumes and train in management of secretions, potentiation of respiratory rhythms and activity.

- Occupational therapy to achieve greater independencies in AVD.

- Study of adaptation and architectural barriers.

- Adaptation of orthoses to avoid joint deformities and assist in displacement.

- $\quad$ Speech therapy for the treatment of swallowing disorder (oropharyngeal dysphagia).

- $\quad$ Fall prevention plan.

\section{Final Thought/Reflection/Conclusion}

The average number of days that severe patients with COVID-19 have been in the ICU 60 days, long enough to develop post-ICU Syndrome (individual and family).

We cannot offer results because we are at the beginning and development of study. We will continue working to provide more data that is useful in the management of future patients.

\section{Bibliography}

1. Needham DM., et al. "Improving long-term outcomes after discharge from intensive care unit: report from a stakeholders' conference". Critical Care Medicine 40(2012): 502-509.

2. Von Blanckenburg P and Leppin N. "Psychological interventions in palliative care". Current Opinion in Psychiatry 31(2018):1

3. Inchausti F., et al. "La Psicología Clínica ante la Pandemia COVID-19 en España”. Clínica y Salud (2020).

4. Heyland DK., et al. "Survivors of acute respiratory distress syndrome: relationship between pulmonary dysfunction and long-term health-related quality of life". Critical Care Medicine 33(2005): 1549-1556.

5. Xie L., et al. "Follow-up study on pulmonary function and lung radiographic changes in rehabilitating severe acute respiratory syndrome patients after discharge". Chest 127.6(2005):2119-2124.

6. Desai S V., et al. "Long-term complications of critical care". Critical Care Medicine 39.2(2011):371-379.
7. Mata Márquez J M. "Impacto de un programa de intervención para la prevención del síndrome post UCI en familiares de pacientes ingresados en UCI". Trabajo fin de Máster, Liderazgo y Gestión de los Servicios de Enfermería, Universidad de Barcelona (2018).

8. Rawal G., et al. "Post-intensive care syndrome: An overview". Journal of Translational Internal Medicine 5.2(2017):90-92.

9. Bados A. Fobia Social. Departamento de Personalidad, evaluación y tratamiento psicológico, Universidad de Barcelona (2009).

10. Petrinec $A B$ and Martin BR. "Post-intensive care syndrome symptoms and health-related quality of life in family decisionmakers of critically ill patients". Palliat Support Care (2017): $1-6$.

11. National Institute for Health and Care Excellence (NICE). Posttraumatic stress disorder. NICE guideline (2018).

12. Sociedad española de Rehabilitación y Medicina física. Recomendaciones sobre movilización precoz y Rehabilitación respiratoria en la COVID-19 de la Unidad de Medicina intensiva, crítica y unidades coronarias (SEMICYUC) y la Sociedad española de Rehabilitación y Medicina física. (SERMEF) (2020).

13. Folstein M., et al. "'Mini-Mental State” a Practical Method for Grading the Cognitive State of Patients for the Clinician". Journal of Psychiatric Research 12.3(1975) 189-198.

14. Dubois B., et al. "The FAB: A frontal assessment battery at bedside". Neurology 55.11 (2000): 1621-1626.

15. Wechsler D. "Adaptación al castellano de la escala de memoria de Wechsler-III". Madrid: TEA Ediciones (2004).

16. Reitan RM and Wolfson D. The Halstead-Reitan Neuropsychological Test (1985).

17. Terol MC., et al. "Propiedades psicométricas de la Escala Hospitalaria de Ansiedad y Estrés (HAD) en población Española". Ansiedad y Estrés 13(2007): 163-176.

18. Beck AT., et al. "An inventory for measuring depression". Archives of General Psychiatry 4(1961): 561-571

19. Echeburúa E., et al. “Escala de Gravedad de Síntomas Revisada (EGS-R) del Trastorno de Estrés Postraumático según el DSM5: propiedades psicométricas". Terapia psicológica 34(2016): 111-128. 
20. Herdman M., et al. "El EuroQol-5D: una alternativa sencilla para la medición de la calidad de vida relacionada con la salud en atención primaria". Aten Primaria 28(2001):425-429.

21. Barraca M J and López-Yarto EL. “ESFA. Escala de satisfacción familiar por adjetivos”. Madrid, España: Segunda edición. TEA, Publicaciones de Psicología Aplicada (1999).

22. Rodríguez Abuín M. "Evaluación y valoración de los Vínculos Interpersonales en el Adultos Ediciones TEA" (2018).

23. Labrador FJ., et al. "Eficacia de un programa de intervención individual y breve para el trastorno por estrés postraumático en mujeres víctimas de violencia doméstica". International Journal of Clinical and Health Psychology 6.3(2006): 527-547.

24. Jarero N and Artigas L. “Conceptualización Teórica sobre el Trauma Agudo y el Estrés Traumático Continuado Basada en el Modelo del SPIA". Iberoamerican Journal of Psychotraumatology and Dissociation (2008).

\section{Assets from publication with us}

- Prompt Acknowledgement after receiving the article

- Thorough Double blinded peer review

- Rapid Publication

- Issue of Publication Certificate

- High visibility of your Published work

Website: www.actascientific.com/

Submit Article: www.actascientific.com/submission.php

Email us: editor@actascientific.com

Contact us: +919182824667 